\title{
Effects of the Processing Time of Recommended Materials and their Usage on the Relevancy to the Course Curriculum
}

\author{
C.N.D. Punchihewa ${ }^{d}$ \\ B.Sc. (Colombo), MLS (Colombo) \\ R.C. Kodikara ${ }^{\mathrm{e}}$ \\ B.A. (Kelaniya), MLS (BrCol)
}

\begin{abstract}
The objective of the present study was to explore the use of materials recommended by the academic members of the University of Moratuwa, identifying the effects of the processing time of the materials on the usage. The circulation statistics of materials ordered during 2007 were analyzed by user categories, year of publication and processing time. Analysis confirmed that frequency of use of materials had no relation with the processing time even though the processing time of the materials was not in a satisfactory level. Zero usage of some materials has created many questions on the recommendations of the academic members. Year of publication of the materials has a direct impact on the usage. The collaboration between the library and the faculties should be further strengthened. Faculties of the University should decide to obtain the assistance of the library academics in designing of courses for different departments of the university.
\end{abstract}

Key Words: $\quad$ Collection Management, Academic Libraries, Data analysis, Academic staff, Circulation systems

\section{Introduction}

This article describes an evaluation of the usage of library items in the discipline of architecture, engineering and information technology against the dates which the items were added to the lending collection. A library always should have a clear understanding about its collection, determining whether the collection meets the needs of the user and educational goals of the institution. According to Henry, Longsaff and Kampen (2008), if the library

\footnotetext{
${ }^{d}$ Senior Assistant Librarian, University of Moratuwa. E-mail: nishan@lib.mrt.ac.lk

e Librarian, University of Moratuwa. E-mail: ruvinik@lib.mrt.ac.lk
} 
does not critically analyze its collection in order to determine how well it is supporting the mission of the university, then the purpose of the library's existence could be called into a question. Adams and Noel (2008) have highlighted collection development as one of most important factor for library quality and also as the most expensive aspect of the library operation.

Through effective collection analysis and assessment, quantitative and qualitative data could be obtained for evaluating the usefulness and utility of the library collection. It assists to determine the budget requirement of the library by focusing how well the library collection supports the needs of the users and the institution. A collection analysis displays the actual scenario of the library holdings to current and new staff of the library. The results of this kind of investigation will direct the librarians to identify whether the investment in the collection is being managed responsibly (Henry, Longsaff and Kampen 2008).

The University of Moratuwa, Sri Lanka, was established as an independent University in 1978. Prior to 1978, it was known as the Ceylon Technical College of Katubedda, which was established in 1893. Today it is one of best technical University in Sri Lanka, comprising three faculties; Engineering, Architecture and Information Technology. Library, University of Moratuwa (UoML) was one of the most prominent engineering libraries in the country. Library, University of Moratuwa is always committed in providing access to both print and electronic resources to the users to support research and curricula. It was the first fully automated University library in Sri Lanka. Processes of the library have been integrated with a library management system called Libsys since 2000.

The library, University of Moratuwa has over 93, 000 items in its collection covering many areas of Architecture, Engineering and Information Technology. More than 75,000 items are housed in the lending section of the library. Average acquisition rate of the library is almost 1600 per year. The library, University of Moratuwa maintains stability of the collection by sending low-use items to a separate location for temporary storage and follows a 
standard weeding procedure to discard the least used or badly damaged items in the collection.

During 2007, Library University of Moratuwa has made all the purchasing of subject materials according to the recommendations of the departments of the University. Recommendations were made by the heads as well as the lecturers of the departments. Fewer acquisitions were acquired according to the requests of the Librarian. Statistics of purchasing and circulation of items recommended by the librarian were ignored in the study. Also the statistics of items added to the reference collections were not considered for the study.

\section{Purpose of the study}

The objectives of this study were finding out the usage of materials recommended by the academic members of the University of Moratuwa and to find out whether library has added the items at the appropriate time or if any delays have caused, whether that had an effect on the low usage.

\section{Methodology}

The present study compared the circulation of the recommended materials (by academic staff members) ordered and accessioned during the period of 2007 against the difference between the accessioned date and the date added to the lending collection. In the preparation for the evaluation, a list of items ordered during 2007 was generated, using the automated library management system. This list included full list of titles and the department which made the recommendation for each material. Another list was generated to evaluate the circulation of each material ordered during year 2007. The checkout statistics used in this study included checkout made by any member of the library or interlibrary loans to users outside of the University. The usage of materials was examined from the date which they added to collection to October 2009.

When considering the usage statistics, the circulation data were collected for each copy, not for each title. The cost of each material purchased during the period of 2007 examined separately. This was analyzed according to each department of the university. After analyzing the data, different graphs were 
generated to compare the usage, cost and the processing time of each material ordered during 2007.

This study had standard problems applied with circulation data. Only checkout statistics were considered in the study. But checkouts alone do not perfectly measure books' usefulness to a patron. In house use of materials was not considered in the study and it has a significant impact on usage of materials.

\section{Results and discussion}

Library University of Moratuwa has purchased six hundred twenty nine (629) items according to the orders made during 2007. There were two hundred and forty four items (244) purchased according to the recommendation of the librarian. Also one hundred fifty one (151) items recommended by the librarian and academic staff members of the university, were added to the reference sections of the library. Among all the ordered and purchased materials during 2007 , there were two hundred and thirty four items (234) recommended by the academic staff members of the university. It included one hundred seventy four (174) different titles of books and other items. The total cost for all the titles was Rs. 1,623,603.14. Table 1 displays the number of titles, number of copies and total cost utilized for purchasing of books and other materials for each department of the University during 2007.

University of Moratuwa has three faculties, namely Architecture, Engineering and Information of Technology. Faculty of Architecture consists of three departments and faculty of Engineering consists of twelve departments (12). Faculty of Information Technology has three departments. According to the findings of the study, all the departments of each faculty have not recommended books for their relevant fields. All three departments of Faculty of Architecture have sent their recommendations to the library. Only eight departments out of twelve of Faculty of Engineering have made to make their recommendations to library for purchasing of books. Out of three, only one department of faculty of Information Technology has forwarded their recommendations of books to the library. 
The usage of these recommended books during the period of study has massive differences. Total of 783 undergraduate students and 145 students of Institute of Technology, University of Moratuwa (ITUM) have used these titles. Compared to the undergraduate students, only 40 postgraduate students have used these materials. Apart from the students 117 staff members of the university have obtained the benefits of materials recommended by different departments.

It was observed that recommended books by an academic staff member for a particular course module do not have much effect on the usage. This was common to all undergraduate students, postgraduate students as well as academic staff members of the university. The reasons may be that books have been added to the collection after the course lectures were completed or were not that relevant to the content of the module. This was mostly because the titles were selected through a publisher catalogue taking the note in the blurb in to consideration. The staff member may be unaware whether the content of the book was relevant to the course (or does not depict the exact content of the book). Also staff member hardly has referred the books he or she has recommended and students were not guided to refer as well. Thus it was noted that the usage was quite low whether the book was added earlier or later.

Table 1- Acquisition of materials for 2007

\begin{tabular}{|c|c|c|c|c|c|c|c|}
\hline Department & $\begin{array}{c}\text { Total } \\
\text { Numb } \\
\text { er of } \\
\text { Titles }\end{array}$ & $\begin{array}{c}\text { Total } \\
\text { Number } \\
\text { of } \\
\text { Copies }\end{array}$ & Total Cost & $\begin{array}{c}\text { Departm } \\
\text { ent }\end{array}$ & $\begin{array}{c}\text { Total } \\
\text { Number } \\
\text { of Titles }\end{array}$ & $\begin{array}{c}\text { Total } \\
\text { Number } \\
\text { of Copies }\end{array}$ & Total Cost \\
\hline Accounts & 02 & 02 & $3,629.80$ & Electronic & 07 & 08 & $144,653.50$ \\
\hline $\begin{array}{l}\text { Architectur } \\
\mathrm{e}\end{array}$ & 06 & 06 & $35,743.72$ & IT Faculty & 01 & 06 & $6,750.00$ \\
\hline Chemical & 16 & 19 & $117,539.30$ & $\begin{array}{l}\text { Quantity } \\
\text { Survey }\end{array}$ & 64 & 64 & $714,327.17$ \\
\hline Civil & 01 & 01 & $1,000.00$ & $\begin{array}{l}\text { Town \& } \\
\text { Country } \\
\text { Planning }\end{array}$ & 08 & 08 & $79,653.63$ \\
\hline Computer & 22 & 48 & $35,594.50$ & Textile & 26 & 29 & $186,714.25$ \\
\hline $\begin{array}{l}\text { Earth } \\
\text { Resources }\end{array}$ & 05 & 08 & $174,082.21$ & $\begin{array}{l}\text { Transport } \\
\& \\
\text { Logistic } \\
\text { Managem } \\
\text { ent }\end{array}$ & 14 & 29 & $50,224.82$ \\
\hline Electrical & 02 & 06 & $69,690.24$ & Total & 174 & 234 & $1,623,603.14$ \\
\hline
\end{tabular}


Another significant feature of the study was very low usage of materials by the postgraduate students. Several reasons have affected to reduce the usage of materials for the postgraduate students. Lack of time to come to the library was a major reason for this low usage of the resources for the postgraduate students. According to the study conducted by Punchinewa and Jayasuriya (2008), $18 \%$ of the postgraduate students have emphasized lack of time as the reason for not using online resources. Same factor may have affected in using print materials. Most of the postgraduate students are employees and most of the postgraduate courses are conducted as part time courses or weekend courses. Therefore majority of the postgraduate students have very less time to spend in the library. Number of borrowing items allocated for postgraduate students depends on the library deposit. Most of the postgraduate students have made the library deposit only for one book. Therefore postgraduate students were reluctant to spend time for borrowing only one book from the library. Though the staff members have recommended these materials, separate study must be conducted to identify the relevancy of these materials to postgraduate courses.

Out of all 174 titles of the items, there were twenty four (24) titles which had zero usage during the period of study. All the other titles have been used at least once by the users. A book recommended by Department of Computer Science \& Engineering had the maximum usage of eighty two (82). Out of all the books purchased during the period of 2007, there were ninety six (96) titles which had the usage between (01) one and five (05). Twenty five (25) titles had been used only once by the users after they were added to the lending collection. Usage levels of the titles has displayed in Figure1.

Out of all the titles which were ordered and purchased during 2007, 13.8\% titles had indicated zero usage after they added to the collection. If these titles have been recommended as the course materials, zero usage of them is a critical factor. It seems that some of the academic staff members have recommended study materials without paying much attention on the relevancy 
of these materials to the courses. More than half $(55 \%)$ of the titles had the usage between 1 and 5 . This figure is also not in a satisfied level, because if these are recommended text materials the usage level should be in a higher level than this. Lack of collaboration between the faculty and the library has directly affected for the low usage of recommended materials. Presently, no library member is participating in the preparation of the curriculum of each faculty or department. This has minimized the opportunity for the academic members to share the experience and the knowledge of the library academics.

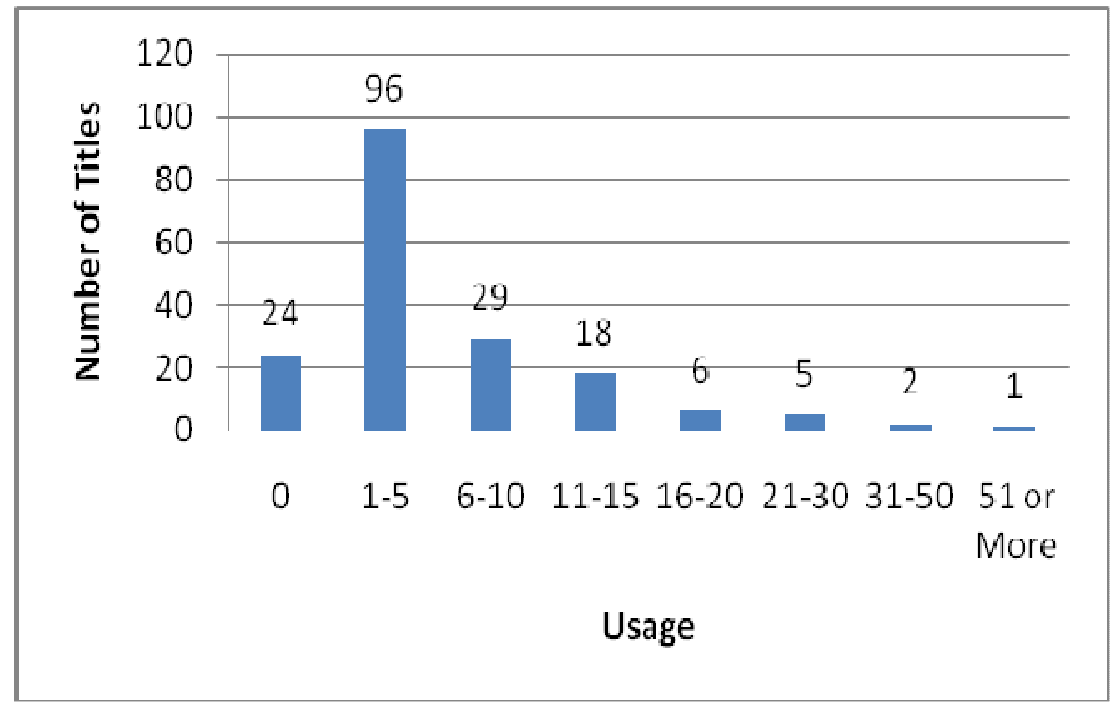

Figure 1 - Usage of the titles ordered during 2007

In this study, the processing time of a book was calculated considering the date which the book was accessioned and the date which the book was added to the lending collection. This processing time had remarkably differed from one title to another. Figure 2 has displayed the number of titles with the processing time.

There were only ten (10) titles which had been processed within a period of one month (30 days) or less. Thirty six (36) titles have been added to the lending collection within one to two months (31 - 60 days) after they were purchased by the library. Also there were thirty three (33) titles which had the 
processing time ten to eleven months (301 - 330 days). Out of 174 titles, there were only sixteen (16) titles which had the processing time close to one year.

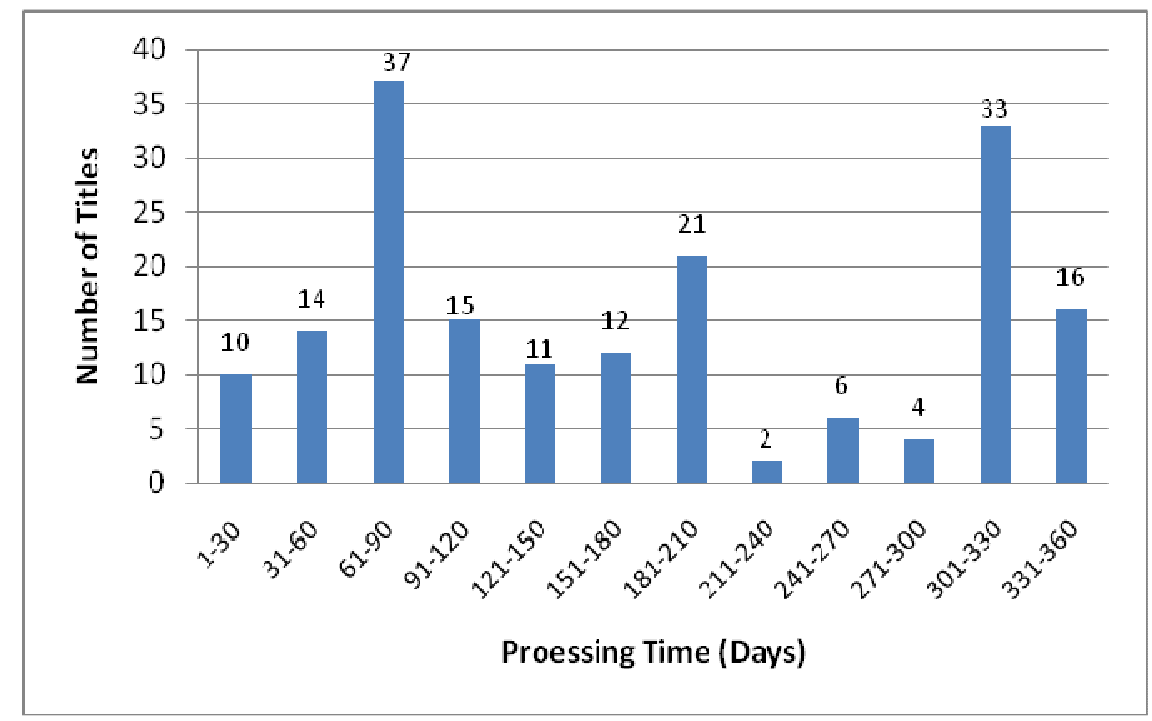

Figure 2 - Processing time of the titles ordered during 2007

If the materials were highly recommended for the courses, the date which the materials were added to the collection has a high impact. It would have a higher usage throughout the year during which the course was being held. The relationship between the usage and the processing time has been plotted in figure 3. According to the graph, a linear relationship was not observed between the two factors. The results of the study have proved that three hundred fifteen days (315) was the processing time for the title which had the maximum usage (82). There were ten titles which had processing time less than one month (30 days). Out of those ten titles, only two titles had the usage more than ten (15 and 11) within the period of study.

The library also seems to have not taken any initiative to process the books at least within 6 months of its arrival. There were few reasons which have affected this delay. Most of the books out of one consignment had to be rebound for RFID usage. Since only the selected hard cover books were added without a delay, the new books with soft cover got delayed due to the binding process. These titles also would have been the most relevant 
reference books for the course. Binders of the library were involved in day to day binding (books damaged by day to day usage), journal binding and attend to the new arrivals for soft binding. All these tasks were handled by only three binders. Thus a delay may have caused in sending the books from acquisition division to cataloguing \& classification division. Process of classification was handled by the academic members of the library, university of Moratuwa. Only one assistant librarian involved in this classification process for all the materials sent by acquisition division of the library. This included all the new books which have to be sent to the lending section, rebound books, materials for reference sections and all the electronic format materials (CD, DVD and VHS). The working ability of the classification person has also acted as the bottle neck in the process from purchasing to circulation. Therefore the study highlights that library needs to expedite the process from purchasing to circulation in a more systematic and efficient manner.

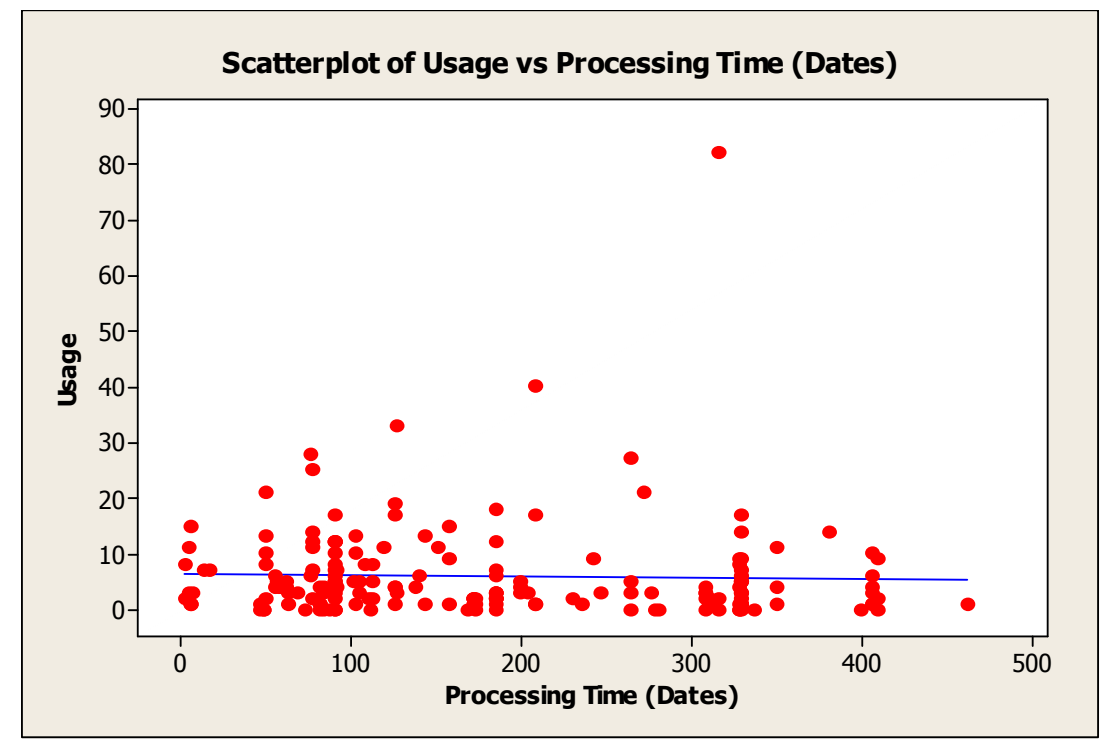

Figure 3 - Correlation between processing time of the materials and usage

In this study, the researcher has analyzed the year of publications of the materials which were recommended during year 2007. Also the study has been further focused on the usage of the materials against the year of publication of the materials. The results are displayed in figure 4 . 


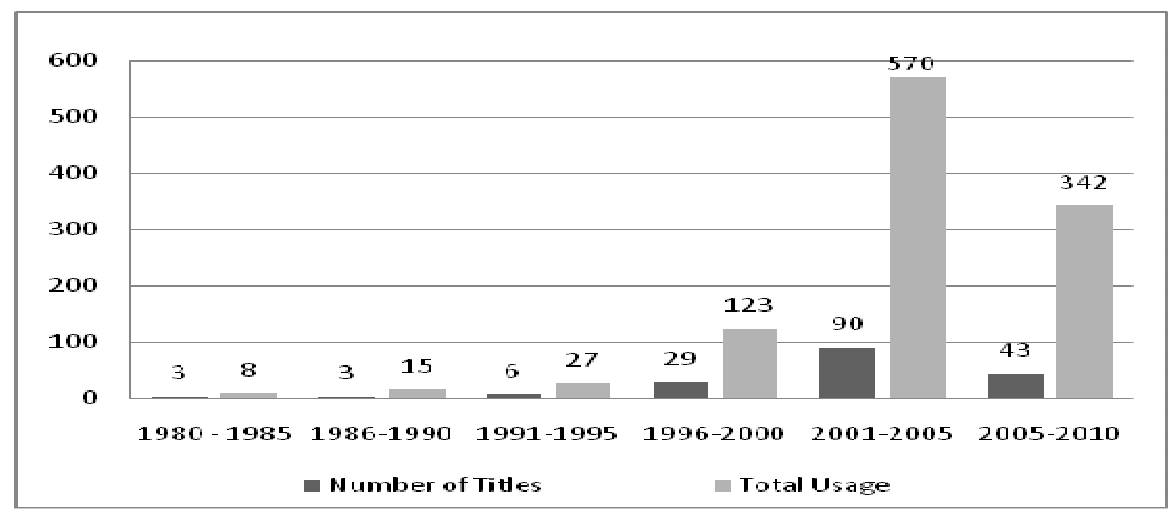

Figure 4 - Year of publication and usage of materials ordered during 2007

According to the results of the study, 1980 was the oldest year of publication for the items which were recommended in 2007. The most recent year of publication was 2008 for the materials analyzed in the study. This has happened due to the delay of delivering the orders forwarded during year 2007. The publishers have delivered these materials in year 2008 and they have provided the materials which had been published in 2008. Majority of recommended materials have been published during $2001-2005$ and those titles (90 titles) had the maximum usage (570 users). The least usage of materials has been highlighted for the materials which had published during $1980-1985$. Due to the rapidly changing nature in the field of engineering, most of the researchers prefer materials published in the past 20 years for their researches (Brush 2007, 59-62). But overall, it was clear that majority of materials recommended by staff members were published after 2001. Staff members have considered the year of publication of materials before they forwarded the recommendation to the library. Because of that, these materials have been utilized by maximum number of users compared to the materials published before 2001.

Table 2 has displayed the average values of the usage and processing time for a title. According to the table 2, average usage for a title is six (06) users (standard deviation 8.584). The average processing time for a title is 181 days (standard deviation 118.04). 
Table 2 - Average usage and processing time

\begin{tabular}{|l|c|c|c|r|r|r|r|}
\hline \multicolumn{1}{|c|}{ Variable } & $\mathbf{N}$ & $\mathbf{N} *$ & Mean & $\begin{array}{c}\text { St } \\
\text { Dev }\end{array}$ & Minimum & Median & Maximum \\
\hline $\begin{array}{l}\text { Processing } \\
\text { Time }\end{array}$ & 181 & 0 & 181.60 & 118.04 & 2.00 & 157.00 & 462.00 \\
\hline Usage & 181 & 0 & 6.00 & 8.58 & 0.00 & 3.50 & 82.00 \\
\hline
\end{tabular}

Library also has taken steps to promote the availability of a recommended book, first by informing the academic staff member through e mail. In addition to this, a list of items added to the collection per week is informed through new additions group (uomlibnewbooks-subscribe@yahoogroups.com) which has the facility to reserve the item. Yet it seems these do not have much impact to increase the usage.

Library never took any interest to increase the usage of these recommended books as it felt that lecturer would definitely add the titles to his reference list as he has recommended the titles to be purchased through the library. In fact the reality was the reference list never listed the books ordered by staff member but different titles were included in the reference list. Thus the library was in a very difficult situation due to non availability of the books that students required.

\section{Conclusions and recommendation}

This study has indicated the successes and failures of the usage of materials ordered during 2007 for library, University of Moratuwa. The circulation data suggest that many precautions should be taken before recommending and purchasing of materials by the academic staff members as well as the librarians. Library has purchased too many unused materials based on the recommendations of the academic staff members. On the other hand, library must seriously think about the processing time of the materials.

At the moment, library academics are not members in any curriculum designing committee of the university. University authority should take a decision to obtain the assistance of the library academics for the course designing of the university. Library must represent as a liaison for the faculties 
and the departments of the University. Providing a prior collection development assessment statement for course or programme proposal is a duty of the library. The librarian should act as a main role in developing reading lists for courses. The collaboration between the library and the faculties should be further strengthened. Librarian should maintain good team relationship with the lecturers of the University by keeping a frequent communication with them. Library should forward this usage statistics for the lecturers who have recommended materials.

Academic staff members of the University must seriously consider about their recommendations before sending them to the library. They should compare the previous usage statistics and most important factor is promoting the students to use the recommended materials.

Library should take initial steps to make smooth line process of acquisition, cataloguing and binding. Working capacity should be increased in the sections of the cataloguing and binding for enhancing the process of classification and binding.

\section{References}

Adams, Brian and Bob Noel (2008). Circulation statistics in the evaluation of collection development. Collection Building 27(2),71-73. Retrieved on September 10, 2009 from www.emeraldinsight.com/0160-4953.htm

Brush, Denise (2007). Circulation analysis of an engineering monograph approval plan. Collection Building 26(2), 59-62. Retrieved on September 10, 2009 from www.emeraldinsight.com/0160-4953.html

Henry, Elizabeth, Rachel Longstaff and Doris Van Kampen (2008). Collection analysis outcomes in an academic library. Collection Building 27(3), 13117. Retrieved on September 10, 2009 from www.emeraldinsight.com/0160-4953.htm

Punchihewa, C.N.D. and Sumana Jayasuriya (2008). Use of online journals and databases: a case study based on University of Moratuwa. Journal of the University librarians association of Sri Lanka 12(1), 124-149

Sherwod, Karen and lan Lovecy (1997). The provision of recommended reading in an academic library. Library Management 18(8), 356-360. Retrieved on September 10, 2009 from www.emeraldinsight.com 